\title{
PEMBENTUKAN KARAKTER ANAK MENURUT PERSPEKTIF KRISTEN
}

\author{
Vikarya \\ Institut Agama Kristen Negeri Toraja \\ Email : vikaryaa22@gmail.com
}

\begin{abstract}
Abstrak
Dalam artikel ini saya akam membahas tentang bentuk-bentuk atau cara kita menerapkan sikap kepada anak yang memiliki kepribadian khusus atau yang pada dasarnya bahwa memang memerluhkan pendampingan. Dengan dukungan dari berbagai pandangan Kristen yang dapat membentuk suatu kepribadian kepada anak, yang memang mememerluhkan perhatian, sebab pembetukan sikap anak seringkali dipengaruhi oleh didikan ornag tau atau keadaan lingkungan sekitarnya. Karena bisa kita ketahui bersama bahwa moral atau sikap anak pada saat ini sudah tidak terjaga dengan baik lagi atau sudah diabaikan. Dengan ini Kristen bisa memberikan suatu pandangan bagi perkembangan anak bahwa anak adalah masa depan bagi keluarga,masayarakat, gereja, dan bangsa.
\end{abstract}

Kata kunci : Karakter, Anak, Kristen

\begin{abstract}
In this article, I will discuss the forms when we apply attitudes to children who have special personalities or which are basically heartbreaking. With the support of various views of Keistm, the dipst forms a personality for children who really need attention because the formation of children is often We can all know that the morals or attitudes of children are careless, sad, these are no longer in good power or have been neglected. With Christianity, we can provide an insight into children's development, children are the future for them. community family. church, and hanga
\end{abstract}

Keywords: Character, Children, Christian

PENDAHULUAN 
Pendidikan karakter anak adalah salah satu upaya pemerintah atau suatu lembaga untuk membangun atau membentuk sosial perkembangan anak sehinggga anak menjadi generasi masa depan yang memiliki moral dan berpendidikan yang baik bagi orang di lingkungan sekitar bahkan untuk masa depannya. Freddy Cardosa mengatakan bahwa Tritunggal Maha kudus adalah fondasi penting dalam kehidupan dan pendidikan Kristen , tiega pribadi ketuhana selalu bekerja sama dalam harmoni yang sempurna dan merupakan dasar dan model untuk pembetukan karakter anak. ${ }^{1}$ Keluarga merupaka tempat yang paling kita sukai atau menjadi awal dari pembantukan karakter pada Anak, ayah dan ibu memilki tanggung jawab dalam memperhatikan seperti apa proses perkembangan atau kehidupan sehari-hari. Pendidikan karakter pada anak yang sering kita jumpai banyak membahasa tentang karakter seorang anak yang tak bosanbosannya di bahas, sebab karakter seorang nak haruslah menjadi suatu perhatian bagi kita. Bagaimana kita memperhatikan karakter atau sikap yang ada pada anak. Dari hal ini pembentukan karakter pada anak perluh untuk kita tingkatkan lagi karena ketika sudah mulai memberikan pendidikan pembentuk karakter seorang anak kita juga akan mulai terbagun atau terjadi dengan melakukan berbagi pendapingan.

Pendidikan pada anak yang menjadi dasar pengajaran dalam keluarga Kristen, keluarga Kristen menajdi tempat pertama pendidikan agama Kristen hal ini yang membuat keluarga akan memaknai hidup sebgai orang Kristen. Disamping itu orang tua yang memiliki peran pentik dalam hal ini mereka juga lah harus menjadi teladan bagi mereka karena kebanyak anak- anak sekarang melakukan sesuatu yang mereka lihat. Orang tua juga memilki tugas yang besar dalam menerapkan atau membentuk pikiran anak dengan kebenaran , kesetian, kejujuran , integritas, loyalitas, kasih dan semua kebaukan lainnya. ${ }^{2}$ Penaladanan berpadanan dengan konsep menyimak/ mengamati dan menirukan sebgai salah satu aspek teori pendidikan agama Kristen, ahli pendidikan sepakat sepakat bahwa keteladanan dan meniru adalah alat yang paling ampuh unruk mengajar iman secara berulang-ulang. Keteladanan adalah hal adalah hal yang pasti di upayahkan oleh orang percaya, dengan tidak bersunggu- sungut dengan orang percayaan. $^{3}$ Pendidikan adalah sebuah proses yang berjalan secara terus menerus, saat ini kita di tantang untuk menginternalisasi makna dan berbagi perubahan yang mengadung dasar orientasi cara

\footnotetext{
${ }^{1}$ Freddy Cardosa, Christian Education. A Guide of the Foundation of Ministry. (united states of America: baker Academic, 2019, 16.

${ }^{2}$ Andar Ismail, Ajarlah Mereka Melakukan ( Jakarta: BPK Gunung Mulla 2019), 30

${ }^{3}$ Rannu sanderan, " EXEMPLARY menemukenali kunci pendidikan iman bagi anak dalam keluarga dan pembelajaran di sekolah".
} 
pandang tersebut. Dengan demikian pendidikan yang berpradigma askites dapat menjadi salah satu upaya trasformasi alternative menuju penumbuhaan hikmat dan displin. ${ }^{4}$

\section{TUJUAN DAN MANFAAT}

Tujuan dari penulisan artikel ini ialah untuk mengetahui peran pembentukan karakter pada anak dalam pandangan Kristen dan bermanfaat bagi kita yang membacanya dan di pergunakan dalam mendidik anak analk dalam membentuk kepribadian mereka menjadi lebiah baik.

\section{PEMBAHASAN}

Dalam pembentukan karakter, pendidikan iman Kristen juga tidak bisa jauh dari kita, karena iman Kristen memberikan kita pengajaran yang bagaimana mendisiplikan diri. Karakter ialah perilaku seseorang yang sering muncul pada saat berinteraksi dengan masyarakat maupun lingkungan yang dilandasi dengan pengetahuan tentang moral, dan kepribadian ilah sejumlah kepribadian sesseorang muncul dalam perilakutanpa adanya penilaian moral, jadi karakter dan kepribadian yang dibentuk melalui katalisasi minat dan antusiasme merupakan modal yang besar untuk menccapi atau mendapatkan sesuatu. ${ }^{5}$ Pendidikan karakter adalah suatu sisitem penanaman nilai-nilai karakter kepada warga sekolah yang mencakup komponen-komponen pengetahuan, kesadaran atau kemauan dengan bertindak melaksanakan nilai-nilai tersebut baik kepada Tuhan, diri sendiri, sesama lingkungan naupun kebangsaan ${ }^{6}$. Pemebntukan karaktyer pada anak biasanya di mulai dari usia 3 atau 5 tahun, pada masa itu anak masih menggunakan pikiran bahwa sadar kerena kemampuan penalarannya belum berkembang. Itulah sebabnya anak yang berusia 5 tahun sangat gampang menerima informasi yang diberikan, sifat anak juga di sni bisa kita lihat dengan adanya mereka dengan berbagai sikap asli yang muncul.

Pembentukan karakter pada anak tidak berhenti samapi di situ sja tetapi akan terus berlanjut, dengan dukungan dari ornag tua, karena merekalah yang menciptakan atau membuat pondasi awal dalam mendidik anak, sebab kepribadian seorang anak akan terlihat dari pola asuh dari anak ini. Bentuk implementasi pendidikan yang diberikan keluaraga anakam memberntuk

\footnotetext{
${ }^{4}$ Rannu Sanderan, “ Disiplin Asketisme dan Harmoni Kontribusi Disiplin Diri bagi Pengembangan pendidikan Kristen"

${ }^{5}$ Rannu Sanderan “ EXEMPLARY menemukenali kunci pendidikan iman bagi anak dalam keluarga dan pembelajaran di sekolah".

${ }^{6}$ Sri Narwanti, Pendidikan Karakter: pengintegrasian 18 nilai pembentuk karakter dalam mata pembelajaran...hal.17
} 
karakter dan sifat dari anak tersebut, bentuk pendampingan memberikan dampak terhadap karakter anak yang dijukan pada lingkuangan salah satu lingkungan di sekolah minggu. Bentuk pendampingan yang diberikan kepada anak, dengan perilaku atau sikap yang di implementasikan anak dalam kepribadiannya merupakan hasil didikan yang diberikan oleh keluraga dengan baik maka karakter dan kepribadian dari anak tersebut juga akan baik.

\section{KESIMPULAN}

Karakter merupakan sesuatu yang mendasar yang di dalam diri seseorang yang memperngaruhi sikap, tindakan, dan cara berfikir sehari-hari, sedangkan pendidikan karakter adalah sebauh proses penerpan bagi seorang anak agar mampu menjadi pribadi yang baik dan berkarakter di bidangnya. Proses pembentukan karakter dimuali dari usia 3 sampai 5 tahun, namun penyempurnaan dan pengembangannya terus berjalan dan membutuhkan waktu seumur hidup. Dengan pandangan Kristen bahwa dengan pembentukan karakter ini anak bisalh lebih mengenal diri sendiri dan mampu mengembangkan potensi yang di miliki dengan mengandalkan kuasa dari Tuhan tanpa menyala gunakan sebab pembentukan karakternya sudah terbentuk.

\section{SARAN}

Sebaiknya dalam pembentukan karakter ini orang tua, guru dan pelayan-peyalan di gereja memfokuskan untuk memberikan penetahuan dan memberikan pandangan kepada kepada anakanak bahwa sagat perluh pembentukan karakter terhadap mereka sebab karakter atau kepribadian seorang anak jauh lebih baik jika di mulai dari usia 3 tahun.

\section{DAFTAR PUSTAKA}

Rannu Sanderan, “ Disiplin Asketisme dan Harmoni Kontribusi Disiplin Diri bagi Pengembangan pendidikan Kristen”

Rannu Sanderan "“ EXEMPLARY menemukenali kunci pendidikan iman bagi anak dalam keluarga dan pembelajaran di sekolah”.

Sri Narwanti, Pendidikan Karakter: pengintegrasian 18 nilai pembentuk karakter dalam mata pembelajaran...hal.17 
Freddy Cardosa, Christian Education. A Guide of the Foundation of Ministry. (united states of America: baker Academic, 2019, 16.

Andar Ismail, Ajarlah Mereka Melakukan ( Jakarta: BPK Gunung MulIa 2019), 30 